\title{
A CONSTRUÇÃO DE IMAGENS NA PESQUISA DE CAMPO EM ANTROPOLOGIA
}

\section{Sylvia Caiuby Novaes $^{12}$}

A fotografia como técnica de criação de imagens por meio de exposição luminosa ${ }^{3}$ é das primeiras invenções de alta tecnologia a interessar antropólogos, que percebem-na como um valioso instrumento em suas pesquisas e a incorporam logo após sua invenção. O uso da fotografia pelos antropólogos será acompanhado pelo fonógrafo (inventado por Edison em 1877) e pelo cinema (cuja patente foi registrada pelos Lumière em 1895). Toda esta nova tecnologia será apropriada pela Antropologia desde o início de nossa disciplina, no sentido de registrar as ocorrências do mundo e apreender a diversidade racial e social que avidamente os cientistas tentavam classificar. ${ }^{4}$ Acreditava-se que estas técnicas permitiam “a exatidão, a verdade, a própria realidade”, suplantando outros registros documentais, como o desenho e a gravura. ${ }^{5} \mathrm{O}$ mimetismo da realidade, propiciado por estas novas invenções provocava enorme fascínio, tanto entre pesquisadores, quanto nos povos por eles pesquisados.

O objetivo deste artigo é refletir sobre a produção de imagens fotográficas ao longo da pesquisa de campo antropológica, a partir de minha própria experiência de pesquisa entre os Bororo de Mato Grosso, de outros grupos que pesquisei, de pesquisas que foram por mim orientadas e de outras das quais me aproximei. Antropólogos em geral adoram viajar. Incluo algumas considerações sobre fotos que captei durante viagens.

\section{A fotografia como recurso de documentação}

A fotografia acompanha os antropólogos em suas pesquisas de campo desde que foi inventada, em meados do século XIX. Boas já trabalhara com ela em 1883, quando fez suas pesquisas na Ilha de Baffin. Entre 1886 e 1902 Boas pesquisou na Columbia Britânica e na ilha de Vancouver no Canadá, no norte da costa do Pacífico. Suas viagens

\footnotetext{
${ }^{1}$ Universidade de São Paulo, Brasil.

${ }^{2}$ Sylvia Caiuby Novaes é Professora Titular no Departamento de Antropologia na Universidade de São Paulo, onde coordena o LISA - Laboratório de Imagem e Som em Antropologia. Agradeço a Leo Fuzer e Mariana Vanzolini pelo tratamento das fotos e diagramação do texto.

${ }^{3}$ A imagem de Niépce, de 1826 é reconhecida como a primeira imagem fotográfica. Sabe-se que como processo ela não é obra de um único criador e seu processo remonta a conceitos como a câmara escura, do século XVI.

${ }^{4}$ Vide Caiuby Novaes, 2010.

${ }^{5}$ Vide Roullé, 2009.
} 
de pesquisa foram financiadas por dois museus, o Smithsonian e o American Museum, que abrigam até hoje sua coleção de fotos. Boas chegou a treinar assistentes de campo entre os Kwakiutl, os Tsimshian e os Sioux Dakota a lhe enviarem descrições etnográficas que ele depois editava para publicação. George Hunt, seu assistente Kwakiutl, passou a usar uma câmera fotográfica por iniciativa própria e suas fotos incluem temas como rituais, dançarinos mascarados, uma série do potlatch, a construção da canoa, mulheres trabalhando, a preparação da comida, etc. Essas fotos correspondiam exatamente ao trabalho que Hunt realizava para Boas, que por sua vez conseguiu uma autorização para que o Bureau of American Ethnology pagasse a Hunt US $\$ 2$ por foto. Hunt trabalhou também junto ao famoso fotógrafo Edward Curtis num projeto sobre a documentação dos Kwakiutl. George Hunt, em uma de suas cartas a Boas comenta sobre a diferença entre as fotografias de artistas e antropólogos. Segundo Hunt, o grande fotógrafo, ao contrário de Boas, havia deixado de fotografar os aspectos mais importantes do ponto de vista Kwakiutl e apenas se interessava por efeitos visuais. Na última fase de sua carreira, ao estudar os gestos e hábitos motores e a influência relativa da cultura nos hábitos corporais, assim como sua teoria sobre a arte como uma elaboração virtuosa dos movimentos rítmicos corporais, Boas utilizou-se intensa e extensamente da fotografia. Para Boas o ritmo era parte essencial de todas as artes: pintura, escultura, dança, música e poesia. Percebendo que precisava de material mais adequado para este tipo de estudo, decidiu empregar uma câmera de filmar e o fonógrafo na viagem que fez a Fort Rupert. O filme não tem estrutura narrativa, nunca foi editado, mas o material bruto foi utilizado como registro dos dados que lhe interessavam. ${ }^{6}$

A expedição organizada pela Universidade de Cambridge ao Estreito de Torres em 1898 fez amplo uso de fotos, filmagens e gravações sonoras em cilindros de cera. Haddon, chefe da expedição, assim como Rivers e Seligman, que dela participavam, estavam interessados em colher dados objetivos, que deixassem de lado a subjetividade. Tanto na expedição ao Estreito de Torres, quanto nas fotos utilizadas por Boas, há um valor documental inegável, são fotos realistas, associadas à observação, evidência, verdade e integridade cultural, atributos típicos do projeto antropológico da época.

\footnotetext{
${ }^{6}$ Sobre o uso que Boas faz da fotografia, vide Jacknis, 1984 e 1992.
} 
Esta postura no uso que a Antropologia faz da fotografia é até hoje a mais recorrente, e perdura como tendência mais geral até por volta dos anos 1960. Veja-se, por exemplo as clássicas fotos de Gregory Bateson em Bali, que junto com Margaret Mead procurava analisar a infância, a socialização e o desenvolvimento da criança e de sua personalidade. As fotografias são para eles instrumento de uma "metodologia sistemática de precisão e integridade". (Edwards, 2011: 162). "Cada fotografia em si pode ser vista como essencialmente objetiva, mas a justaposição de duas fotos diferentes ou contrastivas já é um passo em direção à generalização científica" (Bateson e Mead, 1942: 53, in Edwards, 2011: 164). Trata-se agora de uma "câmera invisível", que procura retratar as pessoas na sua naturalidade e espontaneidade, fotos em que as poses eram vistas como algo que "estragava" a imagem.

Introduzida no Brasil por Hercule Florence em 1833, é com Dom Pedro II que ela se difunde em nosso país. Roquette-Pinto, é o primeiro cientista a fazer uso da fotografia em 1912, quando acompanha por 5 meses a Comissão Rondon, captando inúmeras fotos sobre os Pareci. O uso que este médico e antropólogo faz das imagens aproxima-o da chamada antropologia salvacionista que será anos mais tarde sistematizada por Margaret Mead. O objetivo de Edgar Roquette-Pinto era registrar "antes que principiasse o trabalho de decomposição que nossa cultura vai neles processando". 7

Mesmo que deixando de lado o aspecto salvacionista, é o uso documental da fotografia, sua possibilidade de registro que mais interessa à maioria dos antropólogos que dela fazem uso. Não se trata aqui de fazer uma reconstituição histórica da relação entre a Antropologia e a Fotografia, o que pode ser encontrado em outras obras. ${ }^{8}$ Importa perceber o quanto a fotografia aparece como recurso estratégico que se alia ao caderno de campo, permitindo registrar o que dificilmente conseguimos descrever em palavras, seja pela densidade visual daquilo que registramos, seja por seu aspecto mais sensível e emocional.

Ao longo de cerca de 30 anos de pesquisa entre os Bororo acumulei um acervo de aproximadamente 3.000 imagens, captadas por mim nas diferentes viagens que fiz às várias aldeias entre 1970 e 2.000 . Gostaria de me deter nesta pesquisa que realizei entre

\footnotetext{
${ }^{7}$ Roquette-Pinto, 1917:XIV.

${ }^{8}$ Vide, por exemplo, Edwards, 1992 e 2011
} 
os Bororo para discorrer sobre alguns temas ligados à prática fotográfica na situação de trabalho de campo.

Numa pesquisa de longo prazo, como esta que realizei entre os Bororo e que se estendeu por 30 anos, a presença da câmera e o ato de captar fotografias fazem parte da eterna negociação do pesquisador em campo. Minhas primeiras fotos datam de minha primeira pesquisa de campo numa aldeia Bororo, em 1970. Na época a digital ainda não existia e fotografava em filmes pb, cor e slides, primeiro com uma câmera Pentax e alguns anos depois com uma Nikon.

Fiz várias fotos sobre o tema que então pesquisava: cultura material. Como estas que aqui reproduzo, em que Kiga e Canajó queimam potes de cerâmica.

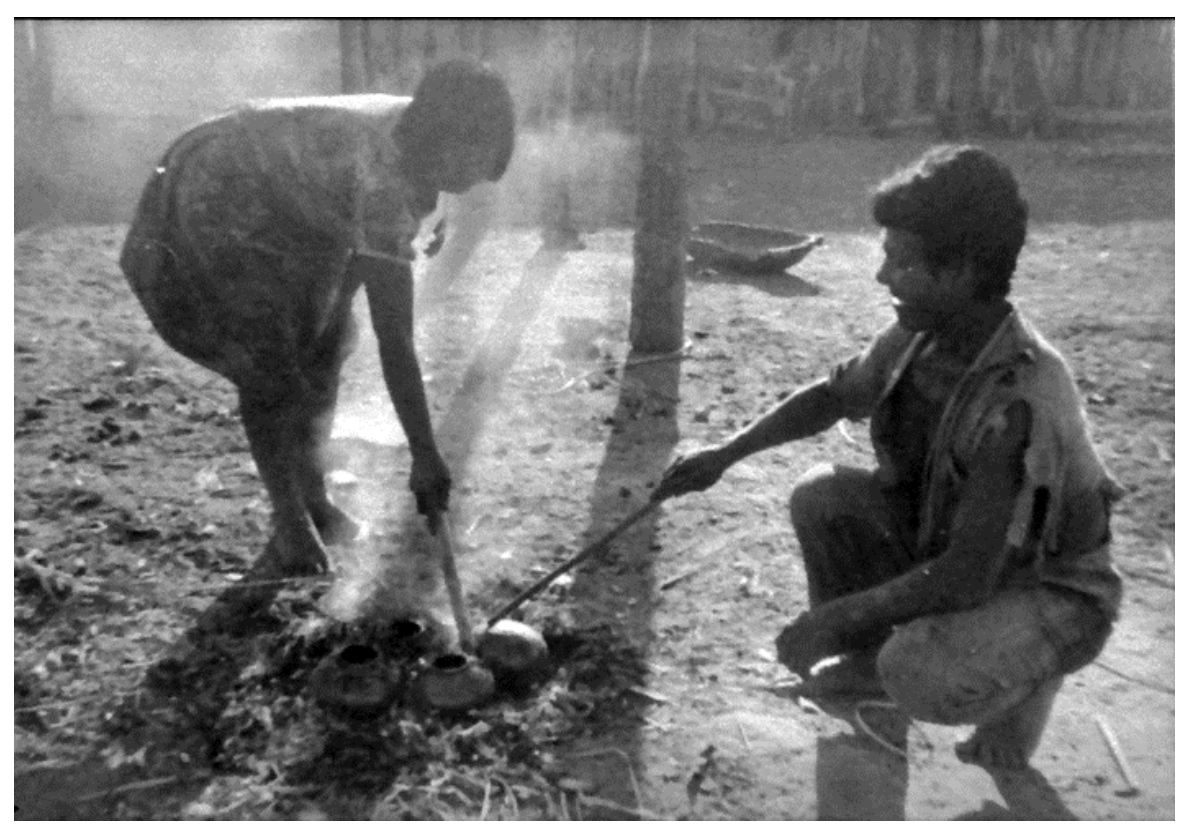



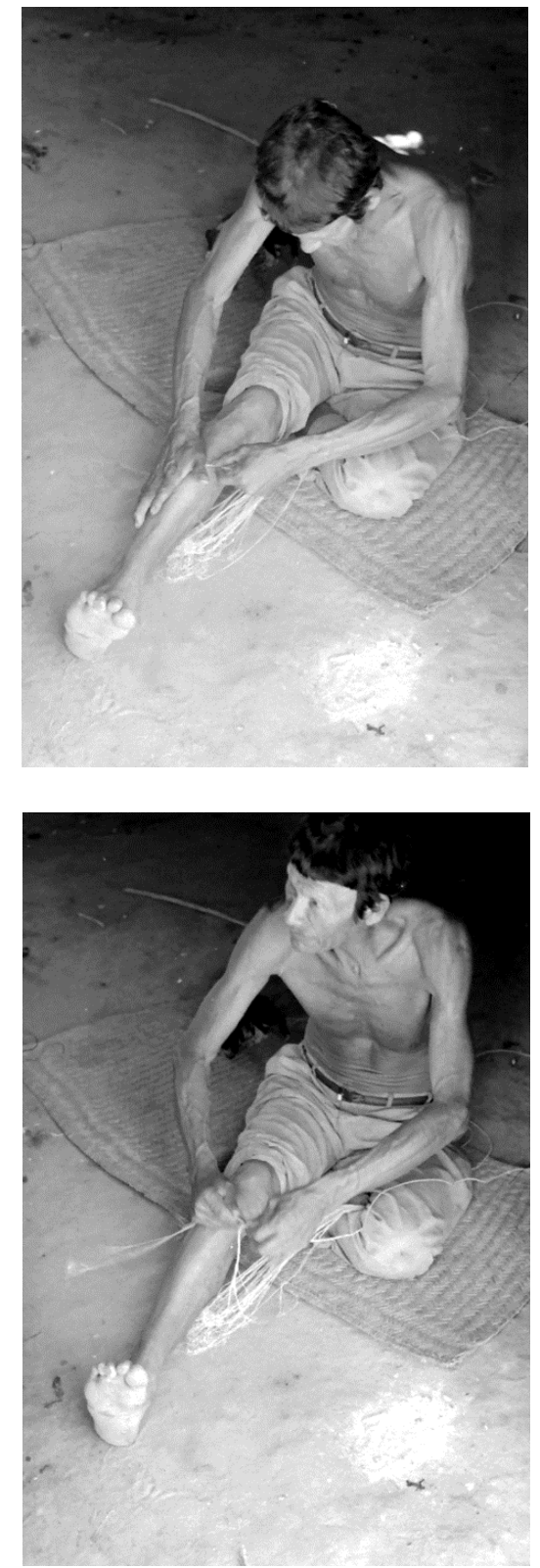

Os Bororo rapidamente entenderam aquilo que eu estava pesquisando e fotografar estes temas era algo que acompanhava sem problema as minhas observações, minhas perguntas a eles e o interesse que eu demonstrava pelo que eles estavam fazendo: as técnicas do trançado na palha, a construção de uma canoa, o modo como enrolavam as fibras da palmeira para fazer uma cordinha de tucum, como se pode ver nas fotos desta página, todo o processo ligado à fabricação de potes em cerâmica, etc. Fiz também inúmeros retratos, principalmente de crianças - e é com elas que os antropólogos mais se relacionam em suas primeiras viagens a campo - e também de alguns adultos de quem mais me aproximei.

No ano seguinte levei todas as fotos que captara em minha primeira viagem, ampliadas em papel fotográfico de maior gramatura, para que "sobrevivessem" às dificuldades típicas da vida na aldeia.
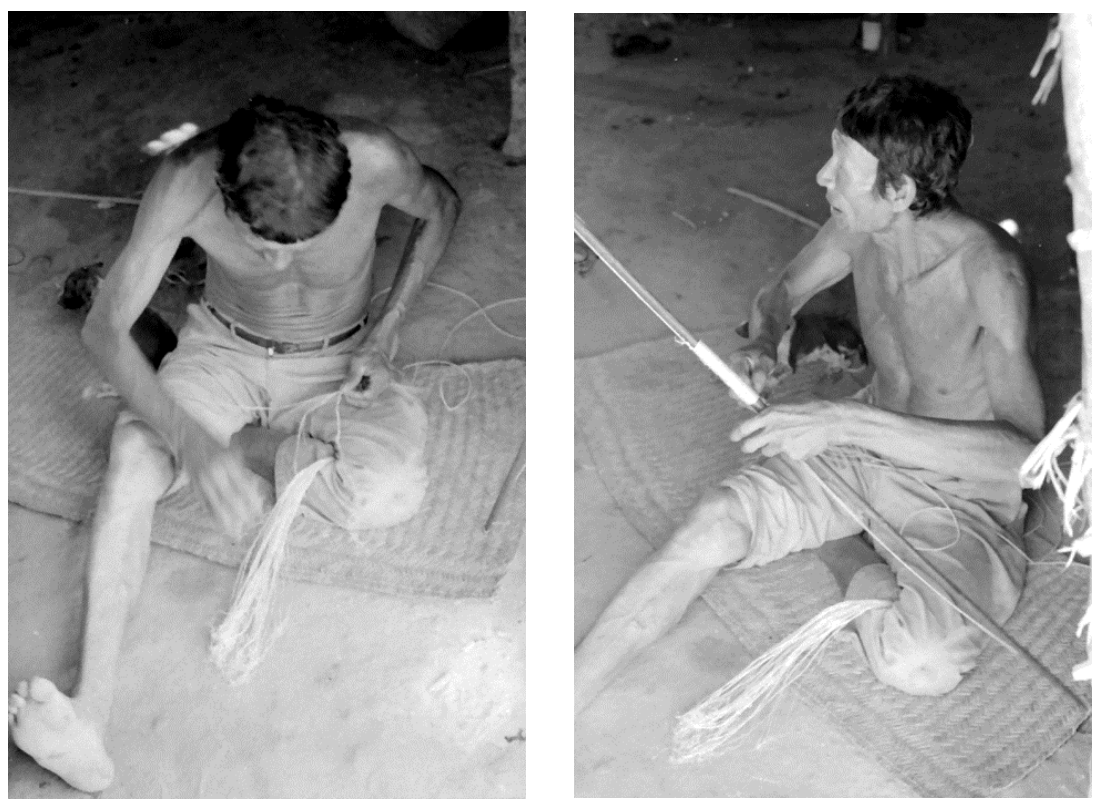

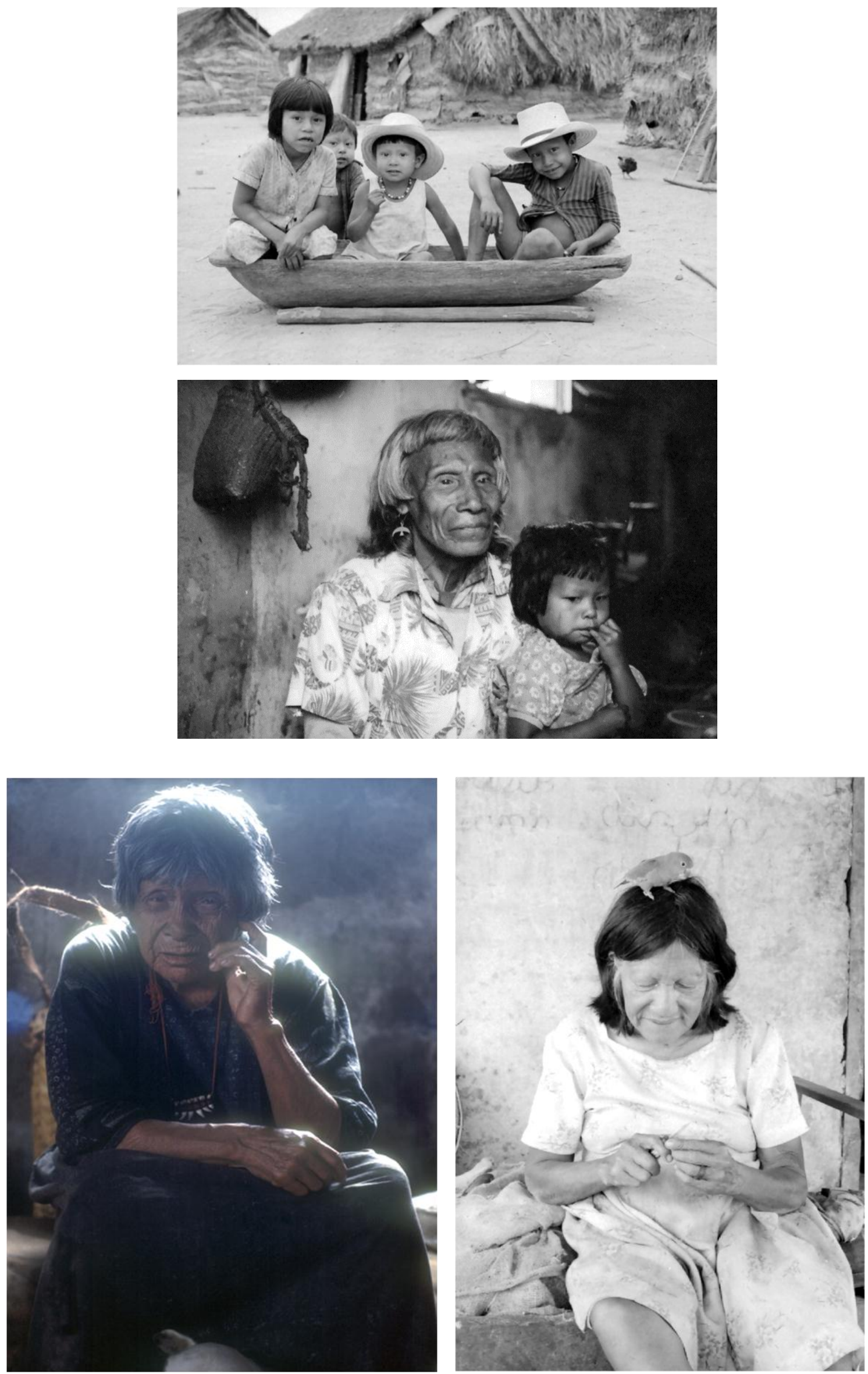
Esta se demonstrou uma estratégia de pesquisa das mais interessantes. Por um lado eu dava as fotos de presente, tendo assim algo que eu mesma fizera e que poderia doar a eles. Por outro lado as fotos desencadeavam conversas que eram cruciais em termos de dados de pesquisa. Qualquer pesquisador sabe o quanto é difícil introduzir o tema que lhe interessa pesquisar a seus interlocutores. As fotografias são neste sentido estratégicas: o tema "não cai do céu", ele é motivado pelas fotos, que permitem ao pesquisador introduzir questões, esclarecer dúvidas, colher ricos depoimentos, acompanhar as discussões que as fotos suscitam entre as pessoas.

Uma outra estratégia de pesquisa, que sempre me pareceu das mais instigantes, foi levar à aldeia filmes que haviam sido realizados muito tempo antes por outros pesquisadores. Levei e exibi na aldeia os filmes realizados em 1935 entre os Bororo por Dina e Claude Lévi-Strauss e, mais recentemente levei outros dois filmes: Matto Grosso the Great Brazilian Wilderness e The Hoax. Ambos foram realizados em 1931 por uma expedição etnográfica e zoológica e são considerados os primeiros documentários com som sincronizado. Matto Grosso narra a longa expedição, que tem seu auge na chegada a uma aldeia Bororo, onde os norte-americanos são recebidos pelos índios, que resolvem organizar uma caçada a uma onça, felino de enorme importância nos ritos funerários Bororo. Deste mesmo material foi editado o outro filme, The Hoax, de apenas 9 minutos. Ambos foram recentemente restaurados pelo Penn Museum, da Universidade da Pensilvania nos Estados Unidos, que solicitou que eu fizesse a tradução das partes faladas em Bororo. Numa viagem à aldeia Bororo do Tadarimana, com o antropólogo Edgar Teodoro da Cunha, levamos e exibimos os dois filmes na aldeia, lá mesmo traduzidos por Beatriz, uma mulher Bororo e legendados por Edgar. Os filmes foram exibidos em uma grande tela de lençol improvisada em um grande barracão. $O$ evento transformou-se num grande acontecimento na aldeia e tivemos que repetir a exibição mais duas noites, tal era para eles a emoção de ver as filmagens realizadas 80 anos atrás.

Quando o pesquisador consegue estabelecer relações de confiança entre aqueles que pesquisa e se o pesquisador tem, além disso, uma sensibilidade treinada, saberá quando e o que pode fotografar. É importante igualmente saber quem pode ver o que, quando se leva de volta as imagens anteriormente captadas. Entre os Bororo, por exemplo, fotos de pessoas mortas recentemente não devem circular. Os Bororo e inúmeras outras sociedades indígenas não vem a foto e sim a coisa nela representada. 
Como se a pessoa representada na imagem se tornasse presente por meio dela. Nesta sociedade todos os bens do morto devem ser destruídos após sua morte e seu nome não deve ser mais pronunciado. A fotografia de um morto impediria que ele deixasse este mundo, de algum modo sua presença ainda seria sentida, o que não agrada aos vivos. ${ }^{9}$ Além disso, mulheres e crianças não podem ver imagens de zunidores ou de algumas representações rituais e cabe ao pesquisador estar atento a estas imagens, para que elas não circulem indevidamente. Na exibição dos filmes de 1931 avisamos aos Bororo sobre a presença destes rituais em algumas cenas; as jovens mulheres, assim que ouviam os sons dos zunidores fechavam os olhos e soltavam alguns gritos de excitação e terror.

Como todos os outros pesquisadores que trabalharam entre os Bororo, fotografei inúmeros rituais, principalmente o funeral, que pode durar até 3 meses. Para fotografar rituais é importante que o pesquisador tenha de antemão uma boa ideia de como o ritual irá se desenrolar, para que possa se posicionar adequadamente e esteja presente em todas as situações consideradas relevantes. Desde que tenha algum tipo de autorização para fotografar, em geral o pesquisador goza de bastante autonomia nestes momentos. Sempre me impressionou o fato de que em momentos rituais, os Bororo estavam tão envolvidos em suas atividades que mal percebiam minha presença com a câmera. Nunca deixei de perguntar a algum adulto que me era próximo, se podia ou não fotografar e nunca me foi negado este direito. Mas vale lembrar que rituais entre os Bororo podem durar muitos dias, implicam grandes investimentos - mate, fumo, carne e outros alimentos, além de toda a parafernália de artefatos e ornamentos rituais - e o antropólogo fotógrafo deve igualmente contribuir nestas ocasiões.

Nunca paguei em dinheiro por uma foto entre os Bororo, por outro lado, nunca deixei de levar na viagem seguinte as fotos que havia captado anteriormente. Nunca solicitei a eles uma autorização por escrito para fotografar. Sociedades indígenas não são "sociedades de contrato" em que uma autorização assinada permita a captação de fotografias ou de uso de imagem. Por outro lado, apesar de ter um grande acervo de imagens de minha pesquisa entre os Bororo, até hoje reluto em publicá-las num livro de fotos, como muitas vezes já me sugeriram. Para isso teria efetivamente que enfrentar a seara de direitos de imagem, que envolvem, no caso de meu acervo, uma autorização da FUNAI, e imagino que de pessoas que representem as aldeias em que fotografei, o que

\footnotetext{
${ }^{9}$ Vide a este respeito Caiuby Novaes, 2008.
} 
já é uma empreitada das mais difíceis. Sociedades indígenas também não são sociedades em que se delegue a um indivíduo a representação de um grupo de pessoas.

Talvez algum dia ainda descubra como fazer para publicar fotos selecionadas de meu acervo. Uma justificativa para tal publicação é que os Bororo são muito orgulhosos de seus rituais, principalmente dos ritos funerários, que podem durar até três meses, entre a morte de um indivíduo e o enterro definitivo de seus ossos em uma baia. Em minha tese de livre docência, Etnografia e Imagem, procuro em um dos capítulos, "Funerais entre os Bororo: Imagens da refiguração do mundo" fazer uma descrição das diferentes fases do funeral Bororo a partir de imagens fotográficas acompanhadas de textos bem curtos. Há uma estética muito particular no funeral Bororo, e uma das figuras mais apreciadas é a da "alma nova", o "aroe-maiwu, como os Bororo o denominam, ou seja daquele que agora representa o morto e que é um indivíduo da metade oposta à do finado e que surge como um grande sol no pátio da aldeia, como se pode ver na foto seguinte. 


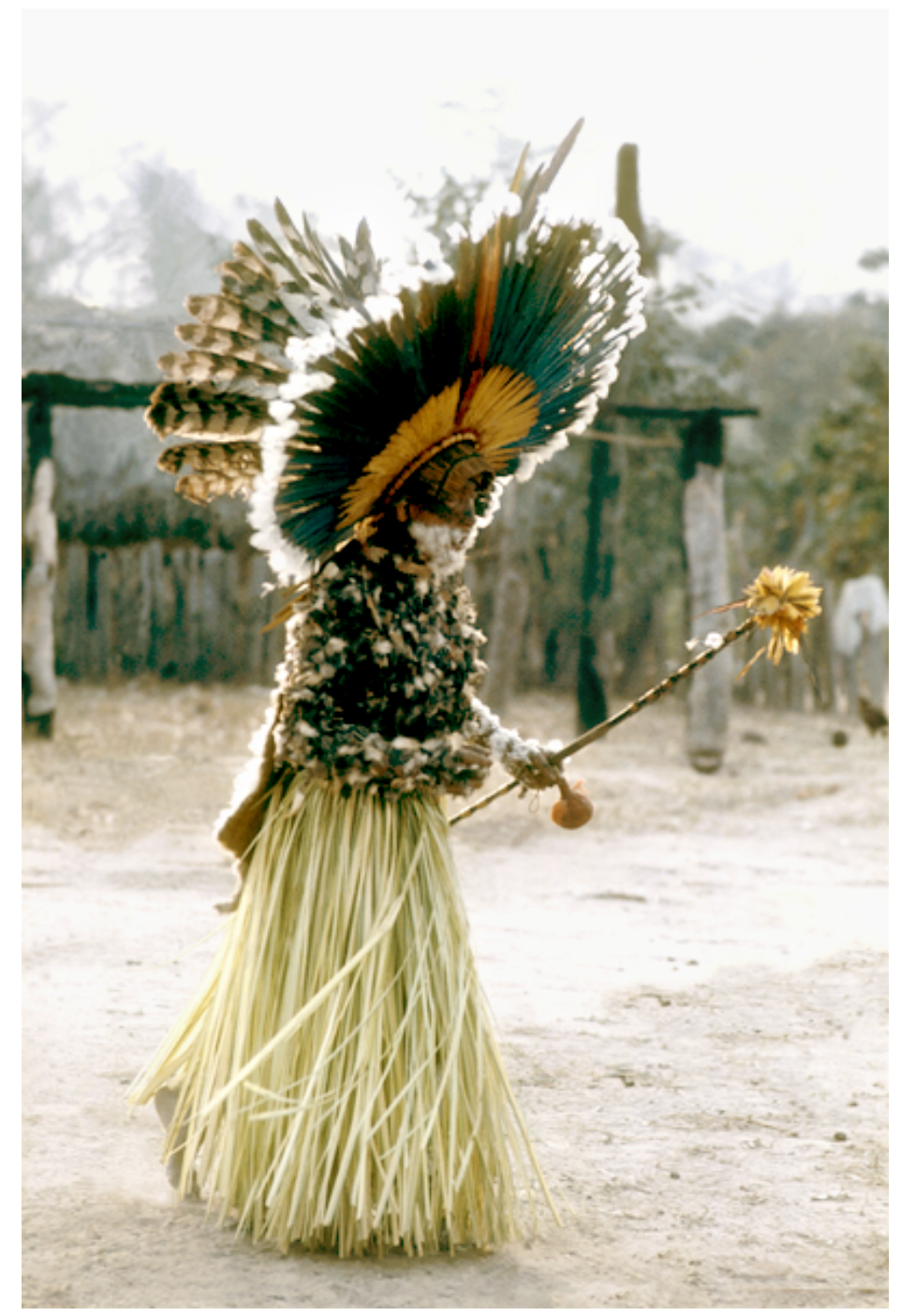

As fotos que captei ao longo da pesquisa entre os Bororo me interessavam em muitos sentidos. Em primeiro lugar como estratégia de pesquisa, pois olhá-las com os Bororo me permitiu acessar temas que de outro modo teria muita dificuldade em introduzir: as relações entre as pessoas, conflitos, determinados aspectos do funeral, etc. Fotografias igualmente permitem registrar aquilo que não necessariamente conseguimos observar em campo. A fotografia é, como diz Milton Guran, uma extensão de nossa capacidade de ver. Sua função é para ele "destacar um aspecto de uma cena a partir do qual seja possível se desenvolver uma reflexão objetiva sobre como os indivíduos ou os grupos sociais representam, organizam e classificam as suas experiências e mantêm relações entre si”. (Guran, 2002: 103). Foi ao observar as várias fotos de rituais de nominação e funerais que captara em minhas pesquisas entre os Bororo que pude descobrir que estes dois rituais - a nominação e o funeral - são, em termos estruturais, 
análogos e invertidos. ${ }^{10}$ As fotografias igualmente permitem registrar aquilo que em palavras perde toda a sua intensidade e dramaticidade, como as escarificações dos corpos dos enlutados ao longo do funeral. Finalmente, a fotografia sempre significou, para mim, a possibilidade de registrar uma estética visual da qual esta sociedade muito se orgulha e que dificilmente conseguiria descrever verbalmente.

Tive igualmente a oportunidade de fazer pesquisas mais curtas. Em 1994 passei um mês no Paquistão registrando em imagens fixas e em movimento o casamento da filha de Shaheen, que eu conhecera em Manchester, quando fazia nesta cidade meu pós doutorado em Antropologia Visual. O casamento paquistanês é, um ritual que dura cerca de 3 a 4 semanas com inúmeras festividades organizadas pelas famílias da noiva e do noivo. Fotógrafos e cinegrafistas estão presentes em todas estas ocasiões, como se vê nas fotos desta página, de modo que minha presença com a câmera não era algo que causasse algum tipo de

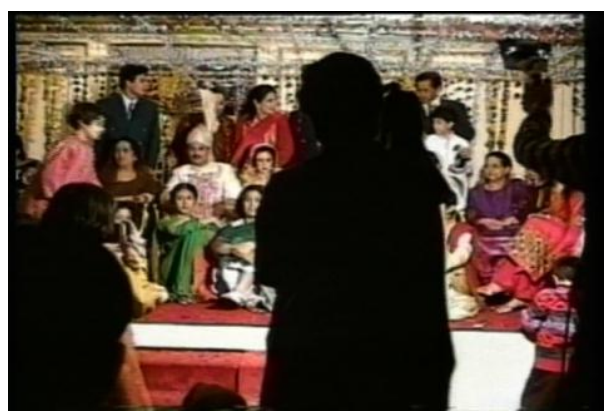
constrangimento. ${ }^{11}$

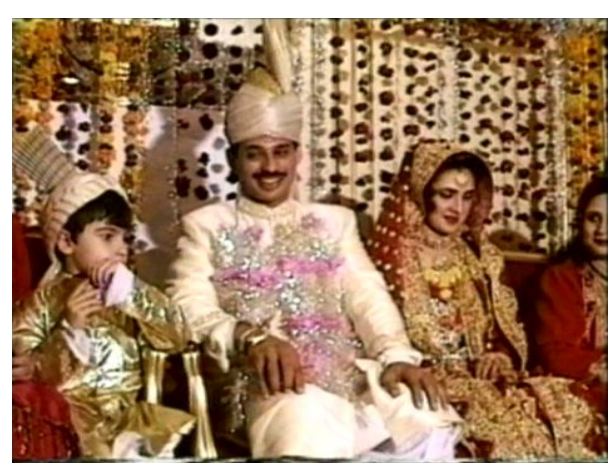

Captei inúmeras fotos em filme pb e cor e filmei com uma câmera Hi8. Depois que fiz a primeira edição do filme resolvi que deveria mostra-lo aos pais da noiva, para que opinassem sobre as imagens. Foi crucial ter feito isso, pois eles me alertaram para algumas cenas que não gostariam que eu incluísse no filme.

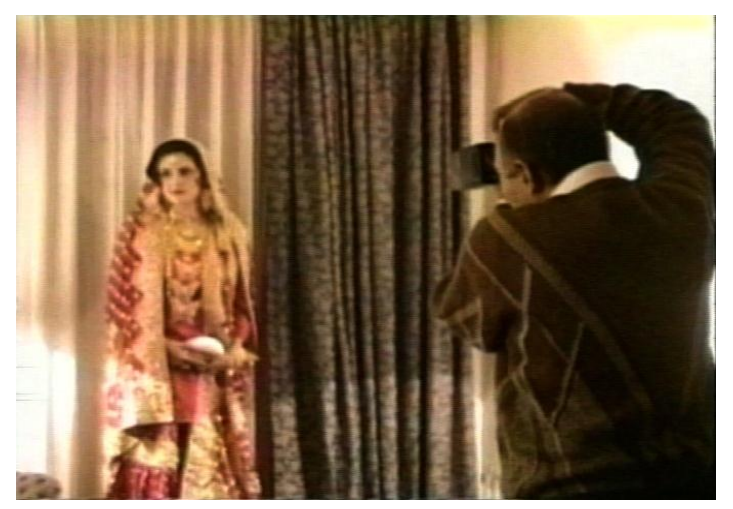
Eram cenas em que moças com menos de 20 anos das duas famílias dançavam sensualmente sendo de perto observadas por mulheres mais velhas. Sabe-se que numa

\footnotetext{
${ }^{10}$ Vide Caiuby Novaes, 2008.

${ }^{11}$ Sobre esta pesquisa no Paquistão vide Caiuby Novaes, 1997.
} 
sociedade em que os casamentos são arranjados estas são ocasiões estratégicas para as mães escolherem suas futuras noras. Os pais da noiva ficaram apreensivos com estas cenas no filme, imaginando que poderiam ser depois censurados pelos pais das moças que dançavam. Só consegui convencê-los de que as cenas não eram impróprias ao mostrar que minhas próprias filhas, que me acompanharam nesta pesquisa, estavam presentes, dançando com as paquistanesas.
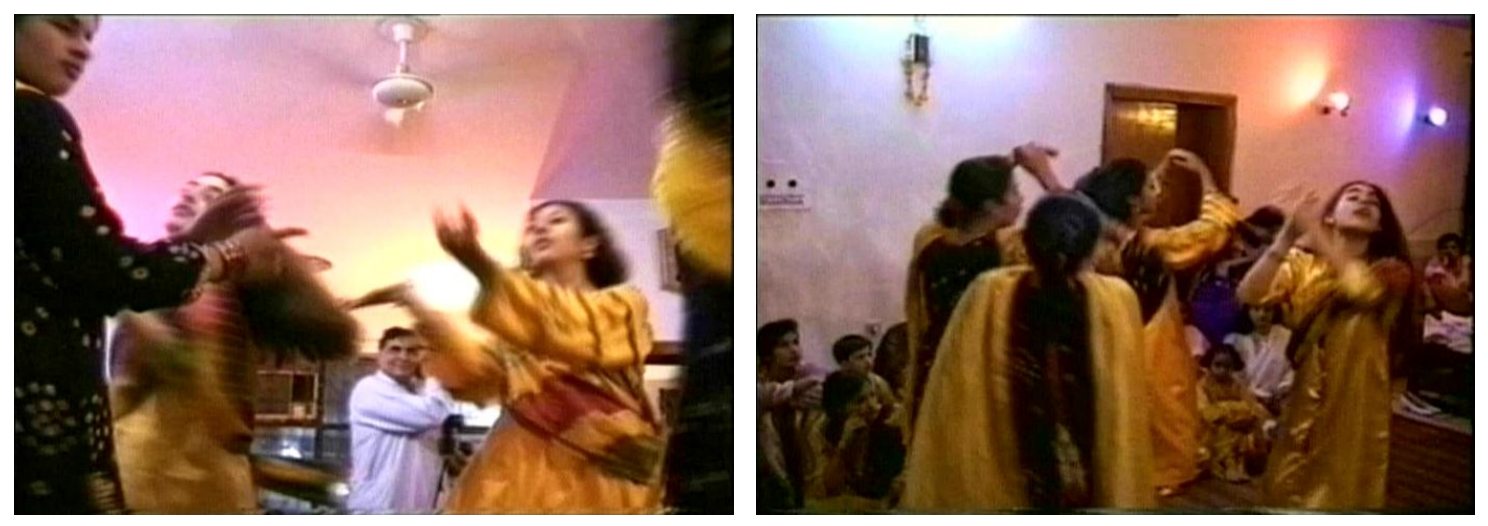

\section{A câmera compartilhada}

Um outro uso importante da câmera fotográfica vem de uma inspiração que tem sua origem no cinema, com os trabalhos de Worth e Adair em 1960 entre os Navajo. Trata-se da capacitação de diferentes segmentos populacionais, pesquisados por antropólogos, no uso da técnica fotográfica, por meio de oficinas que permitem, ao lado da capacitação destas pessoas, situações e oportunidades valiosas para o pesquisador.

Os trabalhos mais conhecidos no Brasil nesta área são aqueles desenvolvidos desde 1980 pelo projeto Vídeo nas Aldeias, coordenado por Vincent Carelli. Em termos de fotografia estes trabalhos tem início no Brasil com Fernando de Tacca (1991) que ofereceu a operários de indústrias de sapato na cidade de Franca, no interior do estado de São Paulo, máquinas simples para que eles fotografassem aspectos de seu cotidiano. No Rio de Janeiro, seguindo esta perspectiva, Barbara Copque (2003) distribui máquinas a jovens moradores de rua em situação de risco, com o objetivo de entender o modo como estes jovens se constroem como sujeitos. Sua análise centra-se nas fotos e no discurso destes jovens sobre elas, permitindo à pesquisadora entrar no universo da rua, da família destes jovens e das inúmeras contradições da instituição familiar para 
essa população. Como diz Barbara Copque: “... a fotografia apresenta-se à etnografia como um valioso meio de incitar o discurso e analisar representações, sobretudo nos espaços onde a antropologia pode encontrar limites, como no caso desta pesquisa, em que a rua se impôs como um obstáculo ao diálogo e o silêncio encontra-se em temas como a família". (Copque, 2003: 277).

A relação entre o pesquisador e as pessoas que ele pesquisa é algo fundamental em qualquer trabalho de campo em antropologia. É esta relação dialógica que marca a qualidade de seus dados. Sem uma mútua relação de confiança a pesquisa de campo não é nem mesmo possível. Nas pesquisas que envolvem imagens, fixas ou em movimento, isso é ainda mais evidente. Principalmente se as pessoas pesquisadas estão em alguma situação de risco, como é o caso dos meninos moradores de rua pesquisados por Barbara Copque.

Poses e encenações estão sempre presentes, principalmente em frente a uma câmera. Isso não diminui a "realidade" da cena ou das pessoas fotografadas. Poses, uma roupa especial, arranjos de cabelo são índices importantes de como as pessoas querem que sua imagem seja vista pelos outros. Correspondem a uma construção de autoimagem que deveria ser de interesse ao pesquisador. Todo mundo quer "sair bem no filme!”. Neste sentido, fotos posadas são igualmente documentais: elas documentam a imagem que o fotografado quer exibir de si.

Ao pesquisar o uso de imagens na Índia, que resultaram no filme Photo Wallahs, David MacDougall, cineasta e antropólogo, aponta para um outro lado da fotografia, que certamente não estava nos planos de Mead e Bateson ao fotografar em Bali: a fotografia "nos oferece a oportunidade de acrescentar algo a nós mesmos e assim rever nossas várias aparências" (MacDougall, 2006: 148). Neste sentido a fotografia não é apenas um duplo ou um espelho que crie um mundo paralelo. MacDougall em Photo Wallahs filmou fotógrafos que realizam fotos de turistas com roupas regionais tradicionais, roupas de bandidos fora da lei, com rifles, pistolas e óculos escuros, e alguns em trajes ocidentais urbanos extremamente sofisticados. Para o fotógrafo hindu entrevistado e filmado por MacDougall, ao assumir uma outra identidade para a fotografia, o fotografado não coloca em risco sua própria identidade. Neste sentido, a fotografia "ajuda na criação de uma realidade, não na sua descoberta ou revelação". (idem, 169). 
Referindo-se a filmes documentários, João Salles afirma que "o documentário não é uma consequência do tema, mas uma forma de se relacionar com o tema". (Salles, 2005:65). Em outras palavras, documentários "não pretendem reproduzir o real, mas falar sobre ele" (idem: 66). Para João Salles a natureza do documentário não é estética ou epistemológica, é ética. Para este cineasta "será documentário todo filme em que o diretor tiver uma responsabilidade ética para com seu personagem”. A natureza da estrutura diferencia o documentário de outros discursos não ficcionais, como o jornalismo e a responsabilidade ética é que afasta documentaristas da ficção. A posição de João Salles é muito próxima àquela da cineasta antropóloga vietnamita, Trinh MinhHa, para quem o importante não é to speak about but to speak nearby. Para Salles o bom documentário é o que tenta transformar o "eu falo sobre ele para nós" em "eu e ele falamos de nós para vocês". (idem, p. 70). Creio que o mesmo pode ser dito da linguagem fotográfica.

\section{Fotos de viagem}

Fotografias facilmente evidenciam a relação entre o pesquisador e as pessoas por ele fotografadas. Em 2004 fiz uma viagem de férias à Etiópia com Tadesse Wolde e sua mulher Elizabeth Ewart, ambos antropólogos. Tadesse é etíope e coordena projetos financiados pelo Christensen Fund ${ }^{12}$ no sul deste país. Por um mês viajamos pelo Vale do Omo, no sul da Etiópia, visitando populações beneficiadas por estes projetos. Captei inúmeras fotos nesta viagem e percebo a diferença entre elas e as que captei ao longo de 30 anos de pesquisa entre os Bororo. Na Etiópia estava em férias e não tinha com as pessoas fotografadas nenhuma relação anterior. Muitas das fotos foram "compradas", como estas que reproduzo abaixo e que foram captadas entre os Mursi. Vender a própria imagem é uma das estratégias concebidas pelos Mursi para arrecadar recursos financeiros. Para estas fotos eles fazem altas produções visuais e não tem nenhum problema em encenar para a câmera. Como poucos, eles conhecem muito bem a "imagem exótica" que interessa aos turistas. Neste caso é o pagamento em dinheiro a base da negociação para a captação de imagens, sem o que elas não são consentidas.

\footnotetext{
12 O Christensen Fund foi fundado em 1957 e é uma fundação privada baseada em São Francisco, nos Estados Unidos, que atua em 5 regiões geográficas do globo, uma das quais o sul da Etiópia, tendo como objetivo a diversidade biocultural. Para mais informações sobre o Christensen Fund vide http://www.christensenfund.org/about/
} 

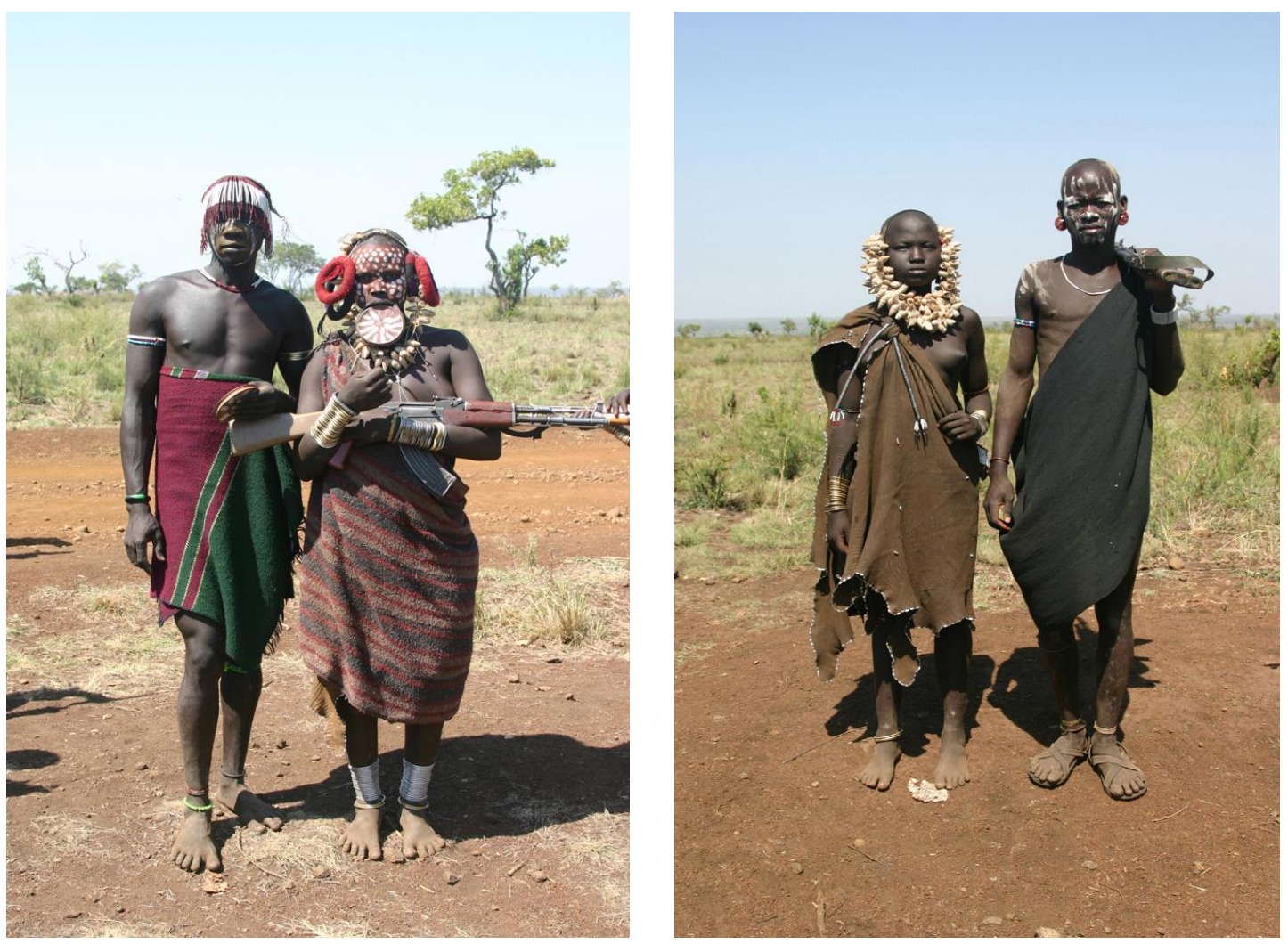

Nesta viagem à Etiópia fiquei absolutamente encantada pelas paisagens e pelas pessoas que encontrava e que contradiziam a imagem que se tem deste país como absolutamente miserável. São vastos campos cultivados por uma enorme diversidade de cereais, para os quais não temos nem mesmo tradução em português. As pessoas são belíssimas e pertencem a uma infinidade de grupos étnicos e linguísticos, com adornos e pinturas corporais igualmente muito diversificados.

Em 2005 fiz uma seleção destas fotos, que expus no XXIX ANPOCS com o título "Imagens da Etiópia - a viagem e o exercício do olhar". Foi interessante observar que eram os pesquisadores negros, presentes no congresso, que mais se detinham nas fotos expostas. Algum tempo depois percebi o quanto eu havia editado meu olhar para a apresentação destas fotos e resolvi fazer uma nova exposição, desconstruindo meu olhar e mostrando como as fotos haviam sido construídas, de modo a revelar apenas aquilo que desejava, deixando de lado tudo que na minha opinião não deveria ser revelado. Reproduzo abaixo algumas destas fotos da segunda exposição realizada em 2007 durante o XXXI Encontro da ANPOCS, que denominei "A construção da fotografia em “A Viagem e o Exercício do Olhar: Imagens da Etiópia". 

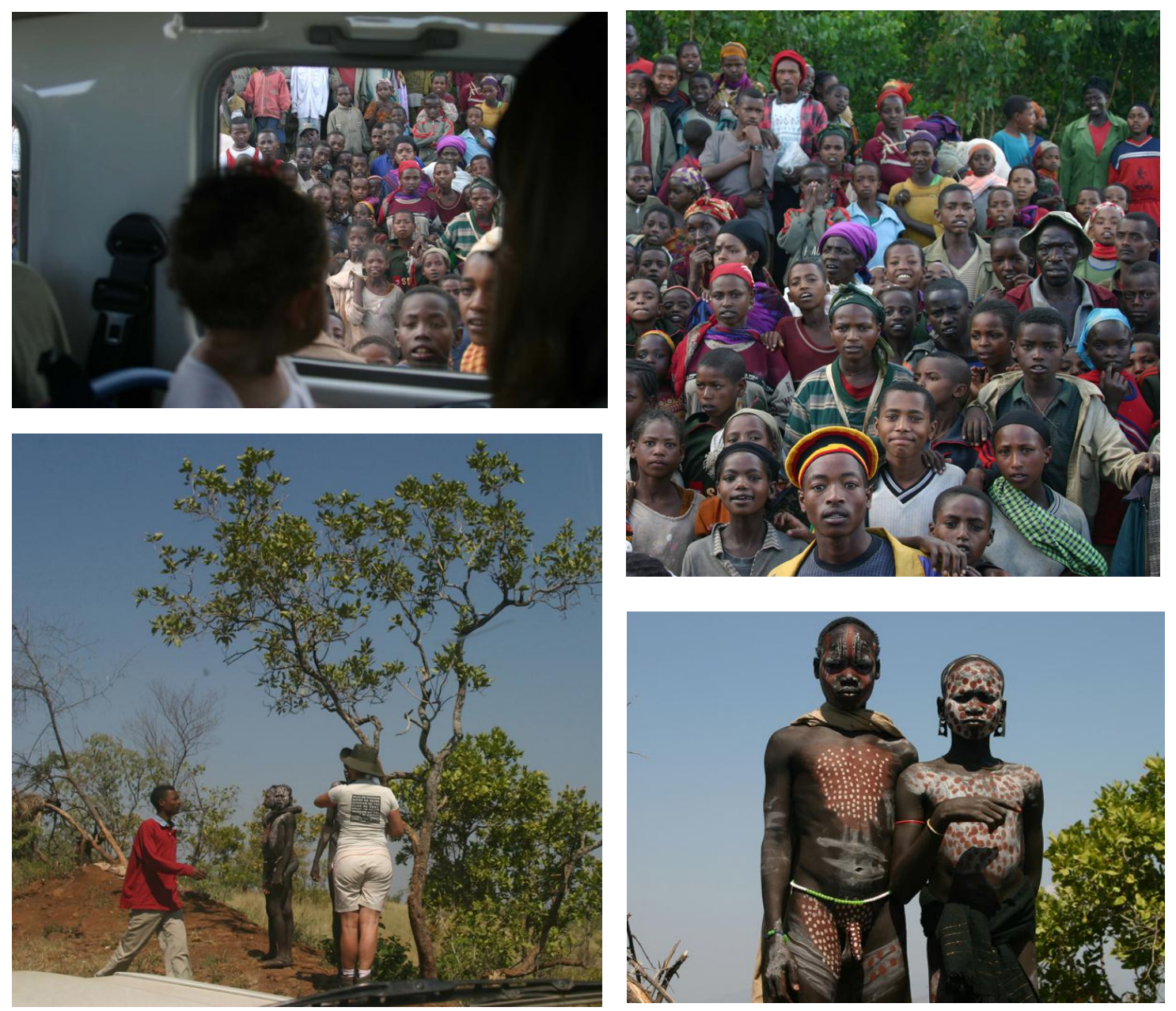

Fotografar nesta viagem à Etiópia foi crucial para perceber o quanto as imagens que eu captara construíam uma outra imagem deste país, que em nada coincidiam com as imagens prévias de desolação e miséria que me assolavam antes da viagem. Percebi igualmente algo óbvio. Imagens fotográficas são fundamentais na construção de imagens mentais de qualquer povo. Na última viagem que fiz à aldeia Bororo do Tadarimana, quando levei os filmes realizados em 1931, fiquei desolada com a quantidade de lixo com que me deparei ao chegar à aldeia. $\mathrm{O}$ acesso a recursos financeiros de toda ordem - aposentadorias, salários, bolsa família - permitiu aos Bororo o acesso a toda sorte de bens de consumo: refrigerantes, iogurtes, brinquedos de plástico, carros velhos, carrinhos de bebê, etc. Sem uma coleta de lixo regular, este lixo se amontoa na aldeia. Parecia-me quase impossível fazer fotos em que o lixo não estivesse presente. Certamente vi muito mais lixo do que o que aparece nas fotos que captei. Mas não estava interessada em foto denúncia e não era esta a imagem que queria fixar. 
Neste sentido, cabe ao pesquisador plena consciência das imagens que ele quer ver publicadas a respeito das pessoas que pesquisa. Este é um outro aspecto da ética do pesquisador, a que já me referi anteriormente. Suas imagens contribuirão certamente para a imagem que se terá daquele povo.

Uma das primeiras sistematizações sobre o uso da fotografia na pesquisa de campo data de 1967, quando John Collier publica Antropologia visual: a fotografia como método de pesquisa (publicado em português em 1973). Collier era um fotógrafo que havia participado do Farm Security Administration, criado por Roosevelt em 1935, no contexto do New Deal, com o objetivo de encontrar soluções para a população rural arruinada pela Grande Depressão de 1929. O objetivo era "introduzir a América aos americanos". Alguns dos fotógrafos que participam do FSA, como Walker Evans, Dorothea Lange e John Collier tornaram-se famosos. Ao documentar a pobreza e as precárias condições das fazendas de algodão, os fotógrafos seguiam uma "pauta" para a tomada das fotos: a relação das pessoas com a terra, a igreja, os celeiros, trabalhadores migrantes e seu cotidiano. Imaginava-se que seria possível controlar a pobreza transformando as práticas ligadas à terra.

A documentação fotográfica obtida pelo FSA é certamente o primeiro e mais abrangente projeto documental sobre a pobreza rural da época da Grande Depressão americana. Foram cerca de 150 mil fotografias, grande parte delas focando as pessoas. John Collier era um destes fotógrafos e anos depois, ao organizar um volume sobre o uso da fotografia como método de pesquisa na Antropologia, Collier procura mostrar o que fazer para perceber o mundo dos outros. Segundo ele (que ficou surdo ainda criança, o que segundo Edward Hall explicaria sua aguçada percepção visual), os ocidentais, ao contrário dos índios Navajo, percebiam o mundo escrito como realidade e as imagens visuais como impressão. Em 1986, com seu filho Malcolm Collier, eles publicam uma versão revista e expandida de Visual Anthropology - photography as a Research Method, em que demonstram não só a pertinência do uso da fotografia para a pesquisa antropológica, mas também a legitimidade desta sub área de nossa disciplina: antropologia da imagem. 


\section{Referências}

BATESON, Gregory e MEAD, Margaret. Balinese Character, a photographic analysis. Special Publication of New York Academy of Sciences, Vol. 2. New York: New York Academy of Sciences, 1942.

CAIUBY NOVAES, Sylvia. "Brasil em Imagens: caminhos que marcam e antecedem a antropologia visual no Brasil”. In: DIAS DUARTE, Luiz Fernando (Org.) Horizontes das Ciências Sociais no Brasil - Antropologia. São Paulo: ANPOCS, 2010. Coedição Instituto Ciência Hoje, Editora Barcarola e Discurso Editorial. p. 457-487.

CAIUBY NOVAES, Sylvia. "Corpo, Imagem e Memória". In: MAMMI, Lorenzo e SCHWARCZ, Lilia. 8 X Fotografia. São Paulo: Companhia das Letras, 2008. p. 113131.

CAIUBY NOVAES, Sylvia. "Imagem, magia e imaginação: desafios ao texto antropológico". In: Mana, v.14, n.2. Rio de Janeiro: UFRJ, 2008. p. 455-475.

CAIUBY NOVAES, Sylvia. "Um casamento no Paquistão: na captura de imagens". In: Cadernos de Antropologia e Imagem, n. 3 (Construção e Análise de Imagem). Rio de Janeiro: UERJ. 1997. p. 107-115.

COLLIER JR, John. Antropologia visual: a fotografia como método de pesquisa. São Paulo: EPU, Editora da Universidade de São Paulo, 1973. (original de 1967 pela Holt, Rinehart and Winston).

COLLIER JR, John e COLLIER, Malcolm. Photography as a Research Method, revised and expanded edition. Albuquerque: University of New Mexico Press, 1990.

COPQUE, Barbara. "Família é bom para passar o final de semana". In: Cadernos de Antropologia e Imagem, v.17. Rio de Janeiro: UERJ, 2003. p. 265-279.

EDWARDS, Elizabeth. "Tracing Photography". In: BANKS, Marcus e RUBY, Jay (Orgs.) Made to be seen - Perspectives on the history of Visual Anthropology. Chicago: The University of Chicago Press, 2011. p. 159-189.

EDWARDS, Elizabeth. Anthropology \& Photography - 1860-1920. New Haven e Londres: Yale University Press, 1992.

GURAN, Milton. Linguagem Fotográfica e Informação. $2^{\mathrm{a}}$ Edição revista e ampliada. Rio de Janeiro: Editora Gama Filho, 2002.

JACKNIS, Ira. George Hunt, Kwakiutl Photographer. In: EDWARDS, Elizabeth. Anthropology \& Photography - 1860-1920. New Haven e Londres: Yale University Press, 1992. p. 143-151.

JACKNIS, Ira. "Franz Boas and Photography". In: Studies in the Anthropology of Visual Communication. Philadelphia: Annenberg School Press, 1984. p. 1 - 60.

MACDOUGALL, David. The Corporeal Image - Film, Ethnography and the Senses. Princeton e Oxford: Princeton University Press, 2006.

MINH-HA, Trinh T. "The totalizing quest of meaning". In: When the moon waxes red. Representation, gender and cultural politics. Nova Iorque, Londres: Routledge, 1991.

ROUILLÉ, André. A Fotografia: entre documento e arte contemporânea. Tradução Constancia Egrejas. São Paulo: SENAC, 2009.

SALLES, João Moreira. "A dificuldade do documentário". In: MARTINS, J. S.; ECKERT, C.; CAIUBY NOVAES, S. O imaginário e o poético nas Ciências Sociais. Bauru: EDUSC, 2005. p. 57-71.

TACCA, Fernando de. Sapateiro: o retrato da casa. 1991. Dissertação de mestrado. Programa de Pós-Graduação em Multimeios, Universidade Estadual de Campinas. Campinas, 1991. 
WOLFF, Francis. "Por trás do espetáculo: o poder das imagens". In: NOVAES, Adauto. Muito além do espetáculo. São Paulo: Editora SENAC, 2004. p. 17-45.

WORTH, Sol e ADAIR, John. Through Navajo eyes. Bloomington: Indiana University Press, 1972.

Recebido em: 08/10/2012

Aprovado em: 11/12/2012 